\title{
Isolated blunt chest injury leads to transient activation of circulating neutrophils
}

\author{
T. Visser $\cdot$ F. Hietbrink $\cdot$ K. M. Groeneveld $\cdot$ \\ L. Koenderman · L. P. H. Leenen
}

Received: 26 February 2010/Accepted: 7 July 2010/Published online: 27 July 2010

(c) The Author(s) 2010. This article is published with open access at Springerlink.com

\begin{abstract}
Introduction The acute respiratory distress syndrome (ARDS) is a severe and frequently seen complication in multi-trauma patients. ARDS is caused by an excessive innate immune response with a clear role for neutrophils. As ARDS is more frequently seen in trauma patients with chest injury, we investigated the influence of chest injury on the systemic neutrophil response and the development of ARDS.

Materials and methods Thirteen patients with isolated blunt chest injury [abbreviated injury score (AIS) 2-5] were included. To avoid systemic inflammation caused by tissue damage outside the thorax, injuries to other regions than the chest did not exceed an AIS of 2. At 3, 9 and $24 \mathrm{~h}$ after injury, the expression of circulating activating molecules on neutrophils and levels of circulating interleukine (IL)-6 were determined. Blood samples from eight healthy volunteers were used as control.

Results Blunt chest injury resulted in the activation of circulating neutrophils, as characterized by a decreased expression of L-selectin (CD62L), CXCR2 (CD182b) and C5aR (CD88) compared to control $(p<0.05)$. Expression of L-selectin, CXCR2 and C5aR was partially restored at $24 \mathrm{~h}$ after injury. In addition, the mean expression of Fc $\gamma$ RIII (CD16) dropped $(p<0.001)$, indicating the
\end{abstract}

T. Visser · F. Hietbrink - K. M. Groeneveld ·

L. P. H. Leenen ( $₫)$

Department of Surgery/Traumatology,

University Medical Centre Utrecht, PO Box 85500,

3508 GA Utrecht, The Netherlands

e-mail: L.P.H.Leenen@umcutrecht.nl

L. Koenderman

Department of Respiratory Medicine,

University Medical Centre Utrecht, Utrecht, The Netherlands recruitment of young neutrophils into the circulation. IL-6 levels increased to a maximum mean concentration of $86 \pm 31 \mathrm{pg} / \mathrm{ml}$ at $24 \mathrm{~h}$ postinjury. None of the patients developed ARDS.

Conclusion Blunt chest trauma caused a systemic inflammatory reaction with transient activation of neutrophils and mobilization of young neutrophils into the circulation. Isolated chest injury, however, was not abundant enough to cause ARDS, so a second hit appears crucial.

Keywords Acute respiratory distress syndrome . Chest injury $\cdot$ Neutrophil $\cdot$ Innate immune response

\section{Introduction}

In multi-trauma patients, the acute respiratory distress syndrome (ARDS) is a commonly seen complication. Important risk factors for the development of ARDS after trauma are severe injury [injury severity score (ISS) $>25$ ] and pulmonary contusion [1,2]. Although the occurrence of ARDS in multi-trauma patients increases considerably with severity of pulmonary contusion, the incidence is surprisingly low in patients with isolated chest injury [2-4].

An excessive innate immune response to tissue injury is considered to be the cause of ARDS. Due to the heterogeneity of injuries present in multi-trauma patients, the specific role of chest injury in the pathogenesis of ARDS is not well known. In this study we investigated the effect of isolated chest injury on the systemic innate immune response to test whether this increased risk of ARDS is caused by priming of the circulating neutrophils or is solely due to local damage. We focused on differences in the phenotype of circulating neutrophils during the first $24 \mathrm{~h}$ after chest injury. Neutrophils are important effector cells 
of the final common pathway of the innate immune response. Activated neutrophils migrate out of the circulation into the alveolar compartment. A massive release of radical oxygen species (ROS) and proteases by neutrophils can cause damage to the parenchyma, which can eventually result in organ dysfunction (ARDS) [5].

Systemic inflammation is characterized by the activation of circulating neutrophils $[6,7]$ and the mobilization of young neutrophils from the bone marrow. Surface receptors of circulating neutrophils have been used to determine the activation of circulating neutrophils in order to discriminate the severity of inflammation and to predict the occurrence of organ failure [6-9]. Systemic neutrophil activation is typically characterized by the shedding of L-selectin (CD62L) and the upregulation of expression of $\alpha \mathrm{M}$ integrin (CD11b) [10-13]. Decreased L-selectin and increased $\alpha \mathrm{M}$ expression have been shown to correlate with ISS and to be associated with the development of posttraumatic complications such as ARDS [14-20]. A previous study by our group showed a significant decreased responsiveness after in vitro stimulation of active Fc $\gamma$ RII (CD32), the main IgG receptor on neutrophils, in multi-trauma patients [20]. Decreased responsiveness of active Fc $\gamma$ RII was more pronounced in patients who developed ARDS or acute lung injury (ALI) compared to patients without complications. Expression of active Fc $\gamma$ RII is under the control of inside-out signals induced by both chemoattractants and cytokines, and seems to be more sensitive to priming stimuli compared with $\alpha \mathrm{M} /$ $\mathrm{CD} 11 \mathrm{~b}$ [21]. The responsiveness of active Fc $\gamma$ RII was found to correlate better with outcome than other neutrophil receptor expressions in preceding observational studies in trauma patients $[11,20]$.

We investigated whether isolated chest injury leads to a systemic innate immune response quantified by the activation of circulating neutrophils. Furthermore, the release of interleukin (IL)-6 was measured as an additional marker for inflammation.

\section{Methods}

\section{Patients}

Patients suffering from chest injury with an abbreviated injury score (AIS) of 2 or more who were admitted to the trauma department of the University Medical Centre Utrecht were included. Patients with injuries with an AIS $>2$ in other regions than the thorax were excluded to reduce systemic inflammation caused by tissue damage outside the thorax. Other exclusion criteria included age $<18$ or $>70$ years, death within $24 \mathrm{~h}$ after admission, and patients with altered immunological status (e.g., corticosteroid use or chemotherapy).
At admission, injury severity score (ISS) [22], new injury severity score (NISS) [23], Apache II score [24], and leukocyte count were determined. All patients were followed until discharge. The presence of ARDS was assessed according to their clinical criteria, as determined in the consensus conferences on ARDS [25].

Blood samples ware taken at approximately 3 (2-4), 9 (8-10) and 24 (22-26) h after the accident to investigate the relationship between chest injury and systemic neutrophil activation. In an in vivo human inflammation model, we saw previously that systemic neutrophil activation is most prominent between 2 and $4 \mathrm{~h}$ after the induction of inflammation [26]. The first measurement time point was therefore set at $3 \mathrm{~h}$ postinjury.

The local ethics committee approved the study, and written informed consent was obtained from all patients or their legal representatives in accordance with the Helsinki Declaration.

Expression of activation markers on neutrophils determined by flowcytometry

The following commercially available mouse-antihuman monoclonal antibodies were purchased for analyzing neutrophil receptor expression by flowcytometry: fluorescein isothiocyanate (FITC)-labeled IgG1 isotype control (clone MOPC-21, BD Pharmingen, USA), Alexa Fluor ${ }^{\circledR} 647-$ labeled IgG1 isotype control (clone MOPC-21, BD Pharmingen, USA), R-phycoerythrin (RPE)-labeled IgG2a isotype control (clone MRC OX-34, Serotec, Germany), RPElabeled IgG1 anti- $\alpha$ M (CD11b; clone 2LPM19c, DAKO, Denmark), FITC-labeled IgG1 anti-L-selectin (CD62L; clone Dreg56, BD Pharmingen, USA), Alexa Fluor ${ }^{\circledR}$ 647labeled IgG1 anti-FC $\gamma$ RIII (CD16; clone 3G8, BD Pharmingen, USA), RPE-labeled IgG2b anti-Fc $\gamma$ RII (CD32; clone FLI8.26, BD Pharmingen, USA), FITC-labeled IgG2a antiCXCR1 (CD181a; clone 42705, R\&D Systems Europe, UK), RPE-labeled IgG2a anti-CXCR2 (CD182b; clone 48311, R\&D Systems Europe, UK), and FITC-labeled IgG2a anti-C5aR (CD88; clone P12/1, Serotec, Germany).

A FITC-labeled monoclonal phage antibody (A27), which recognizes the active configuration of $\mathrm{Fc} \gamma \mathrm{RII}$ (CD32), was manufactured at the Department of Respiratory Medicine at the University Medical Centre Utrecht (MoPhab A27, UMC Utrecht, The Netherlands) [21, 27]. The functionality and configuration of Fc $\gamma$ RII (CD32) on granulocytes is regulated by inside-out control [28]. Visualization of this process by the antibody A27 is a very sensitive means of monitoring the subtle activation of innate immune cells such as neutrophils in vivo.

Blood was collected in a Vacutainer ${ }^{\circledR}$ with sodium heparin as anticoagulant and cooled immediately on melting ice. Blood samples of eight healthy volunteers served as a 
control values. Red cells were lysed with ice-cold isotonic $\mathrm{NH}_{4} \mathrm{Cl}$ [27]. After lysis, white blood cells were washed and resuspended in PBS2+ [phosphate-buffered saline supplemented with sodium citrate $(0.4 \% \mathrm{wt} / \mathrm{vol})$ and pasteurized plasma protein solution $(10 \% \mathrm{vol} / \mathrm{vol})]$. Resuspended cells were incubated for $45 \mathrm{~min}$ on ice with commercially obtained directly labeled antibodies against activation molecules: L-selectin, $\alpha \mathrm{M}, \mathrm{CXCR} 1, \mathrm{CXCR} 2, \mathrm{C} 5 \mathrm{aR}, \mathrm{FC} \gamma \mathrm{RII}$ and $\mathrm{FC} \gamma \mathrm{RIII}$.

After incubation and a final wash, expression was measured on a FACScalibur flow cytometer (Becton, Dickinson \& Co., Mountain View, CA, USA). The neutrophils were identified according to their specific sidescatter and forward-scatter signals.

To measure Fc $\gamma$ RII* $^{*}$ expression, whole blood was incubated with FITC-labeled monoclonal phage antibody A27 for 45 min on ice [11]. Active upregulation of Fc $\gamma$ RII* expression was measured after $5 \mathrm{~min}$ of stimulation of whole blood at $37^{\circ} \mathrm{C}$ with $\mathrm{N}$-formyl-methionyl-leucylphenylalanine (fMLP $10^{-6} \mathrm{M}$ ) to evaluate the responsiveness of the cells for bacterially derived protein products/ peptides. After stimulation, the samples were put on ice again and stained with phage antibody A27. After staining, red cells were lysed, and expression was measured on FACScalibur, as described above.

Data from individual experiments are depicted as the median fluorescence intensity (MFI) of at least 10,000 neutrophils.

IL-6

Plasma samples were obtained at 3,9 and $24 \mathrm{~h}$ after injury and stored at $-80^{\circ} \mathrm{C}$ until further analysis. IL-6 levels were measured by an enzyme-linked immunosorbent assay (ELISA) according to the manufacturer's protocol (Ebioscience, San Diego, USA).

\section{Statistics}

All data are presented as means $\pm \mathrm{SE}$, unless described otherwise. To compare differences in admission variables between patients or control values, the Mann-Whitney $U$ test was used as appropriate. A $p$ value of $<0.05$ was considered significant.

\section{Results}

Patient demographics

Seventeen patients from April 2008 until April 2009 were included in the study. Four patients were eventually excluded because considerable additional injury (AIS $>2$ ) was diagnosed within $24 \mathrm{~h}$ after admission. All of the patients, nine of whom were male and four female, had blunt chest injuries. Thorax AIS varied from 2 to 5 . The injury mechanism and admission characteristics are listed in Table 1. Four patients were under the influence of alcohol at admission. One of them was also hypothermic, with a body temperature of $35.4^{\circ} \mathrm{C}$.

The mean age was $54 \pm 4$ years, the mean ISS $18 \pm 2$, and the mean NISS $23 \pm 3$. One patient was diagnosed with a head AIS of more than 2. This patient suffered from diffuse axonal injury (DAI) without signs of bleeding, edema or compression on CT scan (AIS of 5). Diagnosis was made several days after injury based on clinical presentation. Since the high score assigned to DAI is related to an increased risk of mortality caused by direct brain injury rather than to severity of inflammation, this patient was not excluded from further analysis.

The mean Apache II score was $9 \pm 2$ and the mean hospital stay amounted to $16 \pm 2$ days. Six patients needed mechanical ventilation during their hospital stays for a mean duration of $6 \pm 2$ days. None of the patients developed ARDS. Pneumonia was diagnosed in two patients. One patient developed sepsis due to thoracic empyema and underwent thoracotomy for debridement of the pleural cavity.

Receptor expression on the neutrophil surface

\section{L-Selectin and CD11b}

L-Selectin expression was decreased at $9 \mathrm{~h}$ postinjury $(p=0.002)$ and remained decreased until $24 \mathrm{~h}$ $(p=0.012)$ (Fig. 1a). $\alpha \mathrm{M}$ expression was significantly decreased at $9 \mathrm{~h}$ postinjury compared to control values (Fig. 1b). Although neutrophil activation is typically characterized by $\alpha \mathrm{M}$ upregulation, expression of $\alpha \mathrm{M}$ declined at $9 \mathrm{~h}$ postinjury $(p=0.020)$ to a minimum in this group of patients. This overall decrease in $\alpha \mathrm{M}$ expression is probably due to an increased amount of young neutrophils, which express $\alpha \mathrm{M}$ at low levels [29, 30].

\section{CXCR1, CXCR2 and C5aR}

Neutrophil activation is associated with reduced surface expression of CXCR1, CXCR2 and C5aR [31-33]. After chest injury, circulating neutrophils showed a temporary decline in the expression of chemokine receptors CXCR1 and CXCR2 and complement receptor C5aR (Fig. 1c-e). This decline was statistically significant for CXCR2 and $\mathrm{C} 5 \mathrm{aR}$ at $3 \mathrm{~h}$ postinjury, but not for CXCR1. CXCR2 expression remained low until $9 \mathrm{~h}$ postinjury. It has been demonstrated that, upon activation, CXCR2 internalizes more rapidly than CXCR1 [34], which may explain the 
Table 1 Patient characteristics

\begin{tabular}{|c|c|c|c|c|c|c|c|c|c|c|}
\hline $\mathrm{Pt}$ & Gender & Age & $\begin{array}{l}\text { Mechanism } \\
\text { of injury }\end{array}$ & Diagnosis & ISS & NISS & $\begin{array}{l}\text { Thorax } \\
\text { AIS }\end{array}$ & Apache II & $\begin{array}{l}\text { Leukocyte count } \\
\left(\times 10^{9}\right) / 1 \\
\text { at admission }\end{array}$ & Complications \\
\hline 1 & $\mathrm{M}$ & 25 & MVA & $\begin{array}{l}8 \text { unilateral rib fractures } \\
\text { Bilateral pneumothorax }\end{array}$ & 16 & 25 & 4 & 3 & 12.0 & None \\
\hline 2 & $\mathrm{M}$ & 62 & MVA & $\begin{array}{l}3 \text { unilateral rib fractures } \\
\text { Clavicular fracture } \\
\text { Orbital roof fracture }\end{array}$ & 17 & 17 & 3 & 15 & 8.0 & Pneumonia \\
\hline 3 & M & 51 & Fall from height & $\begin{array}{l}2 \text { unilateral rib fractures } \\
\text { Unilateral pneumothorax }\end{array}$ & 9 & 9 & 3 & 6 & 9.0 & None \\
\hline 4 & $\mathrm{~F}$ & 47 & Fall from horse & $\begin{array}{l}10 \text { unilateral rib fractures } \\
\text { Flail thorax }\end{array}$ & 17 & 17 & 4 & 3 & 19.3 & None \\
\hline 5 & $\mathrm{M}$ & 60 & MVA & $\begin{array}{l}5 \text { Unilateral rib fractures } \\
\text { Unilateral pneumothorax } \\
\text { Unilateral lung contusion } \\
\text { Pancreatic contusion }\end{array}$ & 21 & 29 & 4 & 9 & 17.6 & $\begin{array}{l}\text { Infected epidural } \\
\text { catheter }\end{array}$ \\
\hline 6 & $\mathrm{M}$ & 31 & MVA & $\begin{array}{l}3 \text { unilateral rib fractures } \\
\text { Unilateral pneumothorax } \\
\text { Unilateral lung contusion } \\
\text { Humeral luxation } \\
\text { Clavicular fracture } \\
\text { Diffuse axonal injury }\end{array}$ & 38 & 43 & 3 & 18 & 8.0 & None \\
\hline 7 & $\mathrm{~F}$ & 67 & MVA & $\begin{array}{l}5 \text { unilateral rib fractures } \\
\text { Flail thorax } \\
\text { Unilateral pneumothorax } \\
\text { Bilateral lung contusion } \\
\text { Fracture of proc. transversus }\end{array}$ & 20 & 36 & 4 & 5 & 15.6 & None \\
\hline 8 & $\mathrm{M}$ & 59 & Fall from height & $\begin{array}{l}6 \text { unilateral rib fractures } \\
\text { Unilateral pneumothorax } \\
\text { Unilateral lung contusion }\end{array}$ & 16 & 25 & 4 & 18 & 15.9 & $\begin{array}{l}\text { Thorax empyema, } \\
\text { sepsis }\end{array}$ \\
\hline 9 & M & 69 & MVA & 3 unilateral rib fractures & 5 & 5 & 2 & 5 & 5.0 & $\begin{array}{l}\text { Infected epidural } \\
\text { catheter }\end{array}$ \\
\hline 10 & $\mathrm{~F}$ & 62 & Bicycle accident & $\begin{array}{l}6 \text { unilateral rib fractures } \\
\text { Minor laceration of kidney } \\
\text { Facial hematoma }\end{array}$ & 14 & 14 & 3 & 7 & 8.5 & Pleural effusion \\
\hline 11 & $\mathrm{~F}$ & 53 & Fall from height & $\begin{array}{l}4 \text { unilateral rib fractrures } \\
1 \text { contralateral rib fracture } \\
\text { Scapular fracture } \\
\text { Fracture of cervical vertebral body }\end{array}$ & 17 & 17 & 3 & 2 & 11.2 & Pleural effusion \\
\hline 12 & M & 62 & MVA & $\begin{array}{l}3 \text { rib fractures } \\
\text { Bilateral lung contusion } \\
\text { Minor liver laceration }\end{array}$ & 20 & 29 & 4 & 15 & 7.8 & Pneumothorax \\
\hline 13 & M & 59 & Attacked by cow & $\begin{array}{l}\text { Multiple bilateral rib fractures } \\
\text { Bilateral flail thorax } \\
\text { Bilateral pneumothorax } \\
\text { Bilateral lung contusion } \\
\text { Sternal fracture } \\
\text { Minor liver laceration }\end{array}$ & 29 & 38 & 5 & 6 & 18.9 & Pneumonia \\
\hline
\end{tabular}


Fig. 1 Expression of L-selectin (a), $\alpha \mathrm{M}(\mathrm{CD} 11 \mathrm{~b})(\mathbf{b}), \mathrm{CXCR} 1$ (c), CXCR2 (d), and C5aR (e) on the neutrophil surface over time. Open squares indicate control values from healthy controls $(N=8)$, whereas black squares represent patients $(N=13)$ at 3,9 and 24 h postinjury. $C$, control; hash symbol, time of injury. Data are presented as mean $\pm \mathrm{SE}$

$(* p<0.05, * * p<0.01)$
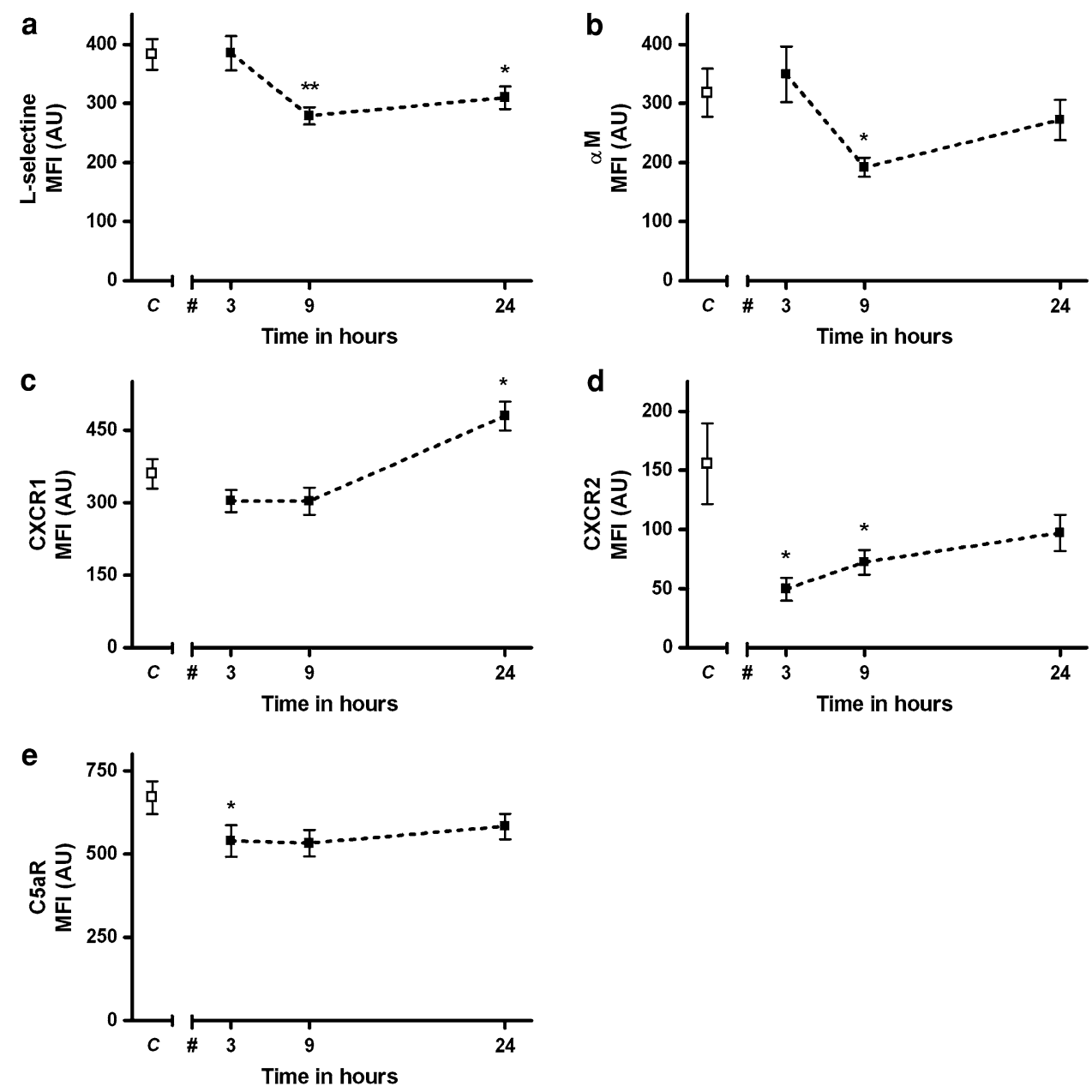

more pronounced decline of CXCR2 compared to CXCR1 in our results. The expression of CXCR2 and C5aR was gradually restored during the first $24 \mathrm{~h}$ after injury, indicating a transient activation of circulating neutrophils. CXCR1 expression increased above control values at $24 \mathrm{~h}$ after injury $(p=0.039)$.

Fc $\gamma$ RII, active Fc $\gamma$ RII and Fc $\gamma$ RIII

Expression of Fc $\gamma$ RII was markedly decreased until $24 \mathrm{~h}$ after injury ( $p<0.010$; Fig. 2$)$. Expression of the active form was slightly lower in trauma patients compared to control values, although this decline did not reach statistical significance. Expression of fMLP-induced active FC $\gamma$ RII, however, was significantly decreased until $9 \mathrm{~h}$ after injury $(p=0.006)$. Expression of Fc $\gamma$ RIII evidently dropped during the first $24 \mathrm{~h}$ after chest trauma $(p<0.001)$. Fc $\gamma \mathrm{RIII}$ is normally expressed at lower levels on young (banded) neutrophils compared with more mature forms [35]. Therefore, this decrease in overall Fc $\gamma$ RIII suggests an influx of young neutrophils.

\section{IL-6 levels}

IL-6 levels were significantly enhanced at $3 \mathrm{~h}$ postinjury compared to control values [mean concentration of $44 \pm 15$ versus $0 \mathrm{pg} / \mathrm{ml}(p<0.001)]$. IL-6 levels further increased to a maximum mean concentration of $86 \pm 31 \mathrm{pg} / \mathrm{ml} \quad(p<0.001$ compared to control values $)$ $24 \mathrm{~h}$ after blunt chest injury (Fig. 3).

\section{Discussion}

In this study we show that blunt chest injury leads to a systemic activation of circulating neutrophils, characterized by the shedding of L-selectin and the downregulation of CXCR2 and C5aR. It furthermore shows that blunt chest injury is associated with the mobilization of young (Fc $\gamma$ RIII-low) neutrophils and with a reduced responsiveness of circulating neutrophils to an inflammatory stimulus.

Although seven patients had a chest AIS of $\geq 4$, and two of these had a bilateral pulmonary contusion, none of these 
Fig. 2 Intrinsic expression of FC $\gamma$ RII (a), active FC $\gamma$ RII (b), fMLP-induced expression of active $\mathrm{FC} \gamma \mathrm{RII}(\mathbf{c})$, and expression of FCR $\gamma$ III (d) on the neutrophil surface during time. Open squares indicate control values from healthy controls $(N=8)$, whereas black squares represent patients $(N=13)$ at 3 , 9 and 24 h postinjury. $C$, control; hash symbol, time of injury. Data are presented as mean $\pm \mathrm{SE}$

$(* p<0.05, * * p<0.01)$
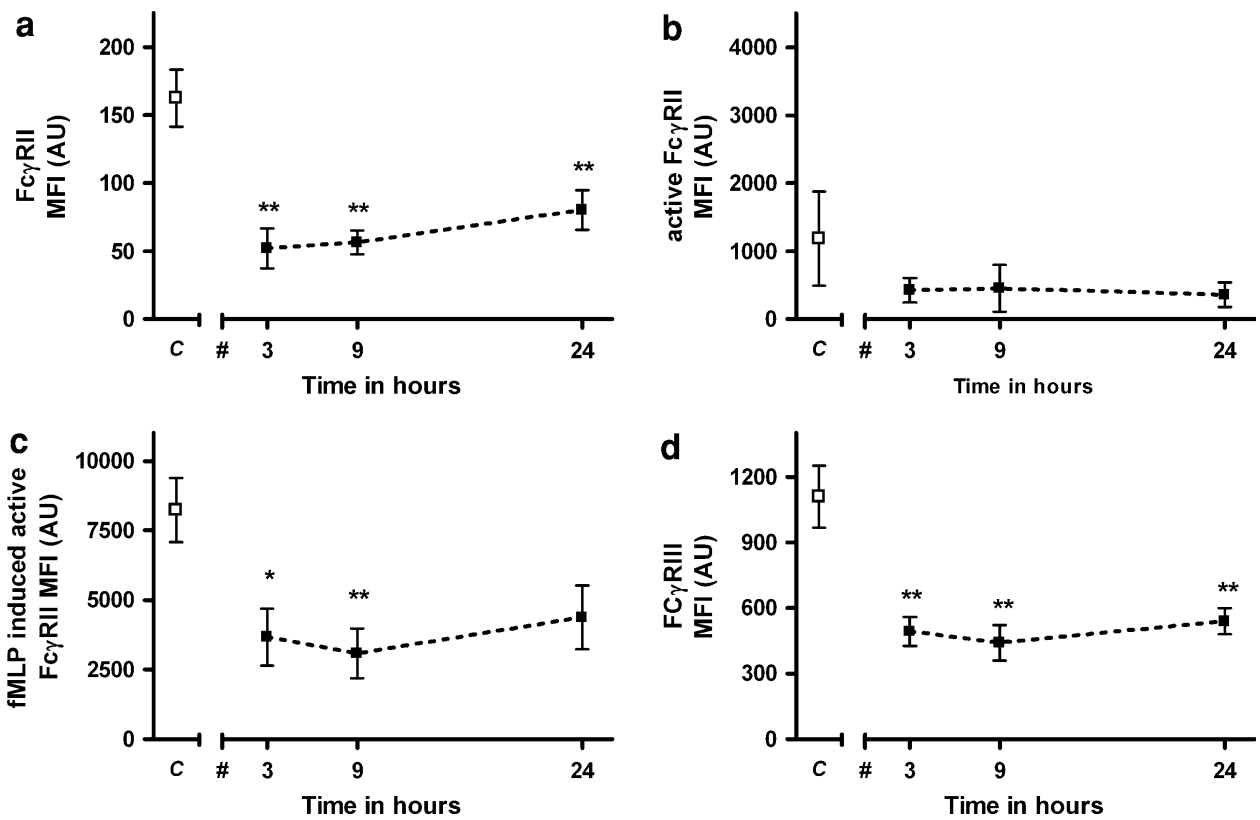

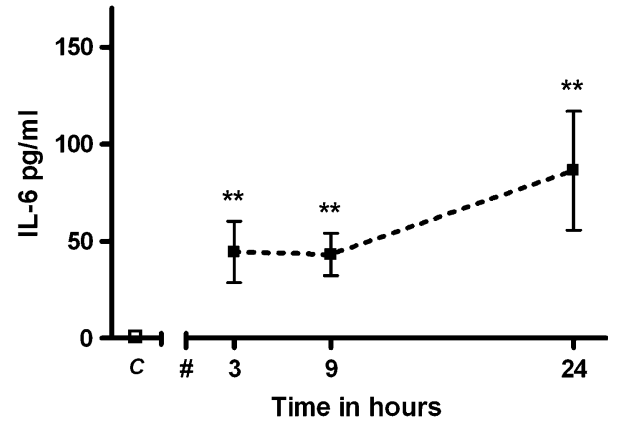

Fig. 3 Levels of circulating IL-6. Open squares indicate control values from healthy controls $(N=8)$, whereas black squares represent patients $(N=13)$ at 3,9 and 24 h postinjury. $C$, control; hash symbol, time of injury. Data are presented as mean $\pm \mathrm{SE}$ $(* * p<0.01)$

patients developed ARDS. Lung injury results in endovascular changes, tissue barrier failure, and locally increased cytokine levels, enabling systemic activated neutrophils to infiltrate the parenchyma. Despite vast local damage in the abovementioned cases, the innate immune response provoked was apparently not abundant enough to cause ARDS. Similar findings were found in an earlier study performed by Maier et al. [4]. This study showed that isolated lung contusion resulted in an increase in circulating IL-6, but it did not cause ARDS. These findings involved patients with minor as well as major lung contusions (based on CT lung injury score). The same study also described an enhanced inflammatory response, with significantly increased levels of circulating IL-6 and IL-8 plus significantly elevated multiple organ failure (MOF) scores in multi-trauma patients with major lung contusions compared to multi-trauma patients with minor or no lung contusions. However, the exact role of lung contusion in the immune response and the occurrence of organ dysfunction was not completely clear in these severely injured patients. The result was biased by an evidently higher ISS in patients with major lung contusions compared to those with minor or no lung contusions. More severe chest injury is most often accompanied by more severe additional injury in at least one of the other regions, resulting in a higher ISS. The same tendency was noticed in our study. The majority of patients who presented at the emergency department with severe chest injury could not be included due to considerable injuries in regions other than the thorax. These challenging inclusion and exclusion criteria resulted in the inclusion of fewer patients, but also a more homogeneous group.

Earlier studies concerning multi-trauma patients demonstrated that fMLP-induced active-Fc $\gamma$ RII expression was decreased in patients compared to controls, and that the expression was negatively correlated with ISS and adverse outcome $[11,20]$. A clear difference in the median fMLPinduced expression of active Fc $\gamma$ RII, measured during the first $24 \mathrm{~h}$ after injury, was seen between patients with ALI/ ARDS (low expression) and patients with an uneventful course (high expression) [20]. The median values for the fMLP-induced expression of active Fc $\gamma$ RII measured in this study are comparable to multi-trauma patients with an uneventful clinical course. These findings support the hypothesis that isolated chest injury induces only a restricted activation of the systemic immune response.

The increased number of circulating neutrophils after chest injury is most likely due to mobilization of young neutrophils, as displayed by a decrease in overall Fc $\gamma$ RIII 
expression. However, delayed neutrophil apoptosis has been described after trauma $[36,37]$. Although this phenomenon remains to be established in vivo, we cannot exclude that the total number of neutrophils are biased by disturbed apoptosis, since apoptotic markers such as annexin $\mathrm{V}$ were not measured.

The fact that isolated chest injury rarely leads to ARDS contrasts with other conditions in which the lung is locally affected and this complication is frequently seen, such as during pneumonia or after aspiration [25, 38, 39]. Presumably, the systemic innate immune response evoked by isolated chest injury is less extensive than that during infection or after aspiration. In a rodent model, Hoth et al. [40] demonstrated that lung injury followed by exposure to $E$. coli lipopolysaccharide (LPS) leads to massive neutrophil infiltration and lung damage, whereas tissue infiltration and damage was far less after LPS or lung injury alone. In addition, serum IL-6 levels were significantly increased compared to LPS exposure or lung injury alone. They concluded that lung injury primes the systemic innate immune response, as was suggested by Maier et al. [4]

In this study we show that the systemic innate immune response caused by isolated chest injury is transient and short. Although IL-6 levels remained elevated until $24 \mathrm{~h}$ after injury, activation of circulating neutrophils was partially restored. However, this mild systemic response may be sufficient to enhance the innate immune response caused by a second hit such as concomitant tissue damage, fat emboli, or infection.

We therefore suggest that lung damage alone is not likely to result in an ARDS, but a synergism between inflammation caused by lung injury and an additional stimulus caused by a second hit results in a markedly increased risk of developing ARDS.

\section{Conclusion}

In this study we demonstrated that isolated blunt chest injury caused transient systemic activation of neutrophils together with a mobilization of young neutrophils into the peripheral circulation. In addition, only severe chest injury (AIS > 4) results in an increased number of circulating neutrophils. However, it seems that chest injury alone is not sufficient to cause ARDS in these cases; a second hit may be needed.

\section{Conflict of interest None.}

Open Access This article is distributed under the terms of the Creative Commons Attribution Noncommercial License which permits any noncommercial use, distribution, and reproduction in any medium, provided the original author(s) and source are credited.

\section{References}

1. Miller PR, Croce MA, Kilgo PD, Scott J, Fabian TC. Acute respiratory distress syndrome in blunt trauma: identification of independent risk factors. Am Surg. 2002; 68(10):845-850; discussion 850-841.

2. Vecsei V, Arbes S, Aldrian A, Nau T. Chest injury in polytrauma. Eur J Trauma. 2005;31:239-43.

3. Miller PR, Croce MA, Bee TK, Qaisi WG, Smith CP, Collins GL, et al. ARDS after pulmonary contusion: accurate measurement of contusion volume identifies high-risk patients. J Trauma, 2001; 51(2):223-228; discussion 229-230.

4. Maier M, Geiger EV, Wutzler S, Lehnert M, Wiercinski A, Buurman WA, et al. Role of lung contusions on posttraumatic inflammatory response and organ dysfunction in traumatized patients. Eur J Trauma Emerg Surg. 2009;35(5):463-9.

5. Henson PM, Johnston RB Jr. Tissue injury in inflammation oxidants, proteinases, and cationic proteins. J Clin Invest. 1987;79(3):669-74.

6. Tellado JM, Christou NV. Activation state of polymorphonuclear leukocytes in surgical patients: characterization of surface receptor expression. Surgery. 1993;113(6):624-30.

7. Rosenbloom AJ, Pinsky MR, Bryant JL, Shin A, Whiteside T. Leukocyte activation in the peripheral blood of patients with cirrhosis of the liver and SIRS. Correlation with serum interleukin-6 levels and organ dysfunction. JAMA. 1995;274(1):58-65.

8. Muller Kobold AC, Tulleken JE, Zijlstra JG, Sluiter W, Hermans J, Kallenberg CG, et al. Leukocyte activation in sepsis-correlations with disease state and mortality. Intensive Care Med. 2000;26(7):883-92.

9. Russwurm S, Vickers J, Meier-Hellmann A, Spangenberg P, Bredle D, Reinhart K, et al. Platelet and leukocyte activation correlate with the severity of septic organ dysfunction. Shock. 2002;17(4):263-8.

10. Garcia-Vicuna R, Diaz-Gonzalez F, Gonzalez-Alvaro I, del Pozo MA, Mollinedo F, Cabanas C, et al. Prevention of cytokineinduced changes in leukocyte adhesion receptors by nonsteroidal antiinflammatory drugs from the oxicam family. Arthritis Rheum. 1997;40(1):143-53.

11. Hietbrink F, Oudijk EJ, Braams R, Koenderman L, Leenen L. Aberrant regulation of polymorphonuclear phagocyte responsiveness in multitrauma patients. Shock. 2006;26(6):558-64.

12. Ley K. Integration of inflammatory signals by rolling neutrophils. Immunol Rev. 2002;186:8-18.

13. McGill SN, Ahmed NA, Hu F, Michel RP, Christou NV. Shedding of L-selectin as a mechanism for reduced polymorphonuclear neutrophil exudation in patients with the systemic inflammatory response syndrome. Arch Surg. 1996; 131(11):1141-1146; discussion 1147.

14. Botha AJ, Moore FA, Moore EE, Kim FJ, Banerjee A, Peterson VM. Postinjury neutrophil priming and activation: an early vulnerable window. Surgery. 1995; 118(2):358-364; discussion 364-355.

15. Giannoudis PV, Smith RM. The effects of trauma and sepsis on soluble L-selectin and cell surface expression on L-selectin and CD11b on leukocytes. J Trauma. 1999;46(5):984.

16. Giannoudis PV, Smith RM, Banks RE, Windsor AC, Dickson RA, Guillou PJ. Stimulation of inflammatory markers after blunt trauma. Br J Surg. 1998;85(7):986-90.

17. Seekamp A, van Griensven M, Hildebrandt F, Brauer N, Jochum M, Martin M. The effect of trauma on neutrophil L-selectin expression and sL-selectin serum levels. Shock. 2001;15(4):254-60.

18. van Griensven M, Barkhausen T, Hildebrand F, Grotz M, Mahlke L, Meier R, et al. L-Selectin shows time and gender dependency in association with MODS. Injury. 2004;35(11):1087-95. 
19. Fowler AA, Fisher BJ, Centor RM, Carchman RA. Development of the adult respiratory distress syndrome: progressive alteration of neutrophil chemotactic and secretory processes. Am J Pathol. 1984;116(3):427-35.

20. Hietbrink F, Koenderman L, Althuizen M, Leenen LP. Modulation of the innate immune response after trauma visualised by a change in functional PMN phenotype. Injury. 2009;40(8):851-5.

21. Kanters D, ten Hove W, Luijk B, van Aalst C, Schweizer RC, Lammers JW, et al. Expression of activated Fc gamma RII discriminates between multiple granulocyte-priming phenotypes in peripheral blood of allergic asthmatic subjects. J Allergy Clin Immunol. 2007;120(5):1073-81.

22. Baker SP, O'Neill B, Haddon W Jr, Long WB. The injury severity score: a method for describing patients with multiple injuries and evaluating emergency care. J Trauma. 1974;14(3): 187-96.

23. Osler T, Baker SP, Long W A. Modification of the injury severity score that both improves accuracy and simplifies scoring. J Trauma. 1997; 43(6):922-925; discussion 925-926.

24. Knaus WA, Draper EA, Wagner DP, Zimmerman JE. APACHE II: a severity of disease classification system. Crit Care Med. 1985;13(10):818-29.

25. Bernard GR, Artigas A, Brigham KL, Carlet J, Falke K, Hudson $\mathrm{L}$, et al. Report of the American-European Consensus Conference on Acute Respiratory Distress Syndrome: definitions, mechanisms, relevant outcomes, and clinical trial coordination. Consensus Committee. J Crit Care. 1994;9:72-81.

26. Pillay J, Ramakers BP, Kamp VM, Loi AL, Lam SW, Hietbrink $F$, et al. Functional heterogeneity and differential priming of circulating neutrophils in human experimental endotoxemia. J Leukoc Biol. 2010; 88(1) 211-220.

27. Koenderman L, Kanters D, Maesen B, Raaijmakers J, Lammers JW, de Kruif J, et al. Monitoring of neutrophil priming in whole blood by antibodies isolated from a synthetic phage antibody library. J Leukoc Biol. 2000;68(1):58-64.

28. Koenderman L, Hermans SW, Capel PJ, van de Winkel JG. Granulocyte-macrophage colony-stimulating factor induces sequential activation and deactivation of binding via a lowaffinity $\mathrm{IgG} \mathrm{Fc}$ receptor, $\mathrm{hFc}$ gamma RII, on human eosinophils. Blood. 1993;81(9):2413-9.

29. Scannell G, Waxman K, Vaziri ND, Zhang J, Kaupke CJ, Jalali $\mathrm{M}$, et al. Effects of trauma on leukocyte intercellular adhesion molecule-1, CD11b, and CD18 expressions. J Trauma. 1995;39 (4):641-4.

30. White-Owen C, Alexander JW, Babcock GF. Reduced expression of neutrophil CD11b and CD16 after severe traumatic injury. J Surg Res. 1992;52(1):22-6.

31. Doroshenko T, Chaly Y, Savitskiy V, Maslakova O, Portyanko A, Gorudko I, et al. Phagocytosing neutrophils down-regulate the expression of chemokine receptors CXCR1 and CXCR2. Blood. 2002;100(7):2668-71.

32. Pillay J, Hietbrink F, Koenderman L, Leenen LP. The systemic inflammatory response induced by trauma is reflected by multiple phenotypes of blood neutrophils. Injury. 2007;38(12):1365-72.

33. Morris AC, Kefala K, Wilkinson TS, Dhaliwal K, Farrell L, Walsh $\mathrm{T}$, et al. C5a mediates peripheral blood neutrophil dysfunction in critically ill patients. AJRCCM. 2009;180:19-28.

34. Richardson RM, Marjoram RJ, Barak LS, Snyderman R. Role of the cytoplasmic tails of CXCR1 and CXCR2 in mediating leukocyte migration, activation, and regulation. J Immunol. 2003;170(6):2904-11.

35. Elghetany MT. Surface antigen changes during normal neutrophilic development: a critical review. Blood Cells Mol Dis. 2002;28(2):260-74.

36. Biffl WL, West KE, Moore EE, Gonzalez RJ, Carnaggio R, Offner PJ, et al. Neutrophil apoptosis is delayed by trauma patients' plasma via a mechanism involving proinflammatory phospholipids and protein kinase C. Surg Infect (Larchmt). 2001; 2(4):289-293; discussion 294-285.

37. Nolan B, Collette H, Baker S, Duffy A, De M, Miller C, et al. Inhibition of neutrophil apoptosis after severe trauma is NFkappabeta dependent. J Trauma. 2000; 48(4):599-604; discussion 604-595.

38. Pepe PE, Potkin RT, Reus DH, Hudson LD, Carrico CJ. Clinical predictors of the adult respiratory distress syndrome. Am J Surg. 1982;144(1):124-30.

39. Wind J, Versteegt J, Twisk J, van der Werf TS, Bindels AJ, Spijkstra JJ, et al. Epidemiology of acute lung injury and acute respiratory distress syndrome in The Netherlands: a survey. Respir Med. 2007;101(10):2091-8.

40. Hoth JJ, Martin RS, Yoza BK, Wells JD, Meredith JW, McCall CE. Pulmonary contusion primes systemic innate immunity responses. J Trauma. 2009; 67(1):14-21; discussion 21-12. 